REVISTA CHILENA DE LITERATURA

Noviembre 2009, Número 75, 271 - 293

\title{
SANTA MARÍA EN LA LITERATURA: DESDE LOS VERSOS POPULARES HASTA RIVERA LETELIER ${ }^{1}$
}

\author{
Mauricio Ostria González \\ mostria@udec.cl \\ Gonzalo Aguayo Cisternas \\ gaguayo@udec.cl \\ Nery Alveal Quintana \\ nalveal@udec.cl \\ Universidad de Concepción
}

\section{SANTA MARÍA EN EL IMAGINARIO PAMPINO}

La vida les fundió un carácter más adentro del rostro moreno, porque el pampino fue un chileno específico, diferentes de cuantos caracterizan a otras regiones (...); el carácter del pampino fluctúa entre una manera especial de mirar su propia existencia con algo de escepticismo y un trago de fatalidad.

(Bahamonde 57)

La historia es de todos, conocida: miles de obreros en huelga bajan desde la pampa a la ciudad de Iquique para hacer oír sus demandas a las autoridades políticas. Las peticiones son razonables, mesuradas y hasta modestas: supresión del pago con fichas, jornales a tipo de cambio fijo, libertad de comercio en la Oficina, protección de los cachuchos para evitar accidentes, prohibición de aprovechar el caliche decomisado, balanzas para los pesos y medidas en las pulperías, escuelas para los obreros, indemnización y desahucio. Los trabajadores son albergados, primero en el hipódromo y luego, en la Escuela Santa María, pero sus demandas no son aceptadas por los empresarios mineros, que exigen su regreso a los lugares de trabajo. La autoridad los conmina a desalojar la Escuela.

1 Este trabajo es parte del proyecto de Investigación FONDECYT, No. 1050593, actualmente en ejecución. 
Los obreros se resisten ${ }^{2}$, y se decreta el estado de sitio. Fuerzas armadas rodean a los huelguistas. Después de varios intentos de persuasión, se da la orden de abrir fuego, produciéndose incontables bajas, mientras reina la confusión y la muerte. Todo transcurre en una semana: entre el 15 y el 21 de diciembre, hace cien años.

Hoy todos conocemos la historia; pero no siempre fue así. Durante mucho tiempo, la llamada historia oficial guardó silencio. Como en tantos otros casos, los hechos se ignoraron convenientemente y no se contó la verdadera historia. En cuanto a la prensa de la época, primero fue la censura y, después, como lo advierte muy adecuadamente Pedro Bravo Elizondo (1997), la ficción, en favor de la versión oficial. Pero el episodio se conservó en la memoria popular, la que se expresó a través del canto y la poesía; perduró en relatos testimoniales y fue recuperado por poetas y narradores que convirtieron sus textos en eficaces sustitutos de aquella historia silente.

La matanza de Santa María forma parte de una historia -la de las luchas obreras-y de un imaginario cultural: el del salitre. Gentes oriundas de muy diferentes lugares, etnias y culturas se congregaron en la pampa calichera, en medio del desierto más árido del mundo, para dedicarse a las faenas extractoras del nitrato. En ese medio geográfico y laboral, se entreveraron perfiles económicos, sociales y culturales que se conjuntaron, sin confundirse del todo, para producir una historia compleja, contradictoria, agónica. Junto a chilenos del norte y del sur, llegaron peruanos, bolivianos, argentinos, estadounidenses, ingleses, italianos, alemanes, yugoslavos, árabes y chinos, todos en busca de un destino que terminó configurando una identidad cultural perfectamente diferenciada, aunque heterogénea y compleja. Efectivamente, la cultura pampina fue una cultura sincrética y mestiza (mineros, cateadores y peones del norte chico, campesinos del sur, campesinos indígenas del Perú y Bolivia, pobladores de los puertos aledaños, pequeños comerciantes, funcionarios públicos, maestros, policías, administradores, aventureros, jefes, casi siempre europeos). Aunque era una sociedad mayoritariamente masculina, las mujeres cumplieron importantes roles no solo como amas de casa: realizaron trabajos en las calicheras, en las 'cantinas' o pensiones, en los grupos artísticos, en las escuelas y también como prostitutas ${ }^{3}$.

La cultura pampina fue particularmente urbana o casi urbana: las oficinas (emplazamiento de las instalaciones industriales y habitacionales) y los campamentos (conjunto de viviendas) fueron pueblos habitados por los trabajadores y sus familias. Los pobladores se organizaron en clubes, cofradías, conjuntos teatrales y musicales, filarmónicas, mutuales, sindicatos. Al mismo tiempo, dentro de la más pura lógica capitalista, se estructuró una muy estricta sociedad clasista que se manifestó en la demarcación de los espacios, en las relaciones laborales, en la calidad de vida, en las

2 "Nosotros - declaraban los huelguistas a un periódico local- no abandonaremos la ciudad, mientras no se atiendan favorablemente nuestras peticiones, y en caso contrario, solicitar del gobierno nos envíe al Sur, donde el trabajo no falta" (El Tarapacá, miércoles 18 de diciembre de 1907).

3 Leer Hombres y Mujeres de la Pampa (2002) de Sergio González Miranda. 
formas de tratamiento, etc., con repercusiones más allá de la pampa, alcanzando los puertos aledaños, por donde se exportaba el llamado oro blanco ${ }^{4}$. Los espacios que ocupaban las casas de jefes, administrativos y obreros estaban rígidamente demarcados y vedados sus accesos a quienes no pertenecieran por oficio o condición a cada sector. También se segregaba en los lugares públicos (plazas, teatros, escuelas, pulperías) y en las actividades sociales (fiestas, espectáculos).

El imaginario pampino incorporó relatos heroicos y picarescos, leyendas y mitos, se vinculó con la historia y la geografía; integró tradiciones heterogéneas, creó personajes, inventó lugares fabulosos, y produjo las necesarias transformaciones idiomáticas para hacer del español un recurso expresivo eficaz, a través del cual manifestar sus penas y agravios, sus amores y aspiraciones, sus temores, creencias, preocupaciones y sueños.

Así, a pesar de su efímera existencia, surgió en la pampa un espacio cultural nuevo, inédito, propio, que tuvo su expresión en normas de comportamiento, organización del trabajo, principios valóricos y en los diversos códigos que organizaron sus formas de vida y sus sistemas de comunicación. Entre ellos, la lengua hubo de acomodarse, especialmente en su léxico, pero también en los otros componentes del sistema a las nuevas necesidades expresivas de la emergente comunidad cultural, cuya razón de ser afincaba, como queda dicho, en las actividades laborales que constituyeron el eje decisivo de su surgimiento y consolidación, el condicionamiento indispensable de su convivencia social.

Tal vez, uno de los testimonios más vivos de esa cultura ya extinta se encuentra en la literatura del salitre que ha sabido recrear, no solo la vida dolorosa de los mineros y sus familias, sino también importantes aspectos de su lengua, sobre todo aquellos que dicen relación con la forma de proyectarse en el mundo, a través de la imaginación. En la literatura de la pampa salitrera, esas formas lingüísticas permanecen vivas en las bocas de personajes y narradores y desde el interior de los textos no siguen hablando de sus angustias y esperanzas. En el seno del imaginario pampino, el episodio de Santa María ocupa un lugar privilegiado y se ha constituido en referente con carácter mítico, tanto en la tradición lírica popular, como en la llamada narrativa del salitre.

\title{
2. SANTA MARÍA Y LA POESÍA POPULAR
}

\author{
Vamos al puerto, dijeron, vamos, \\ con un resuelto noble ademán, \\ para pedirles a nuestros amos \\ otro pedazo no más de pan. \\ (Cit. en González et al. 413)
}

4 Iquique, "ha sido construida con materiales andinos, coloniales, republicanos y salitreros... es también expresión de procesos mundiales, de estilos, símbolos y fuerzas sociopolíticas que estructuran la vida urbana de la sociedad occidental. Será un punto nidal en la política del abastecimiento de recursos naturales de los imperios coloniales, especialmente el imperio británico" (Sánchez 303). 
La poesía oral cumplió en la cultura pampina, junto a las funciones expresivas inherentes al género, otras más narrativas y aún informativas. Si nos remontamos a principios del siglo XX en Chile, donde los índices culturales y alfabéticos de la clase trabajadora eran muy limitados, se comprenderá la relevante función social que la poesía oral -o de origen oral- cumplió como vehículo de expresión popular o de relato informativo y aun imaginario ${ }^{5}$.

Y es que al menos en sus inicios, la cultura pampina se mueve fundamentalmente en la oralidad. Ésta es la forma de comunicación básica, de expresión de sensaciones y sentimientos, de manifestación de su filosofía de vida y también, la manera de narrar sus historias, de informar o de entretener; todo esto, en el contexto de una cultura preferentemente popular. Tal tradición se conserva, incluso, cuando los versos son escritos y la cultura asume ciertos rasgos letrados. Así lo manifiesta, por ejemplo, el poeta popular Rosario Calderón: "decidí componer en décimas las estrofas que van a continuación. Esta forma de versos es la que más les gusta a mis compañeros de trabajo, para quienes escribo y nada me importa la crítica de los eruditos literarios" (González et al. 323).

Como se sabe, la poesía popular se nutre de un continuo tradicional, trazado por el verso romance, a menudo acompañado de música ${ }^{6}$, en el que se vacía la temática que alude a las cuitas, vivencias, cosmovisiones, sentimientos y emociones de los trabajadores salitreros. Casi sin modificar su estructura sintáctica, pero, claro, mutando su soporte material (lo oral por lo escrito), la poesía pampina, asume los rasgos de la Lira Popular. No obstante, el cambio de escenario (del campo a la oficina) no deja indemne al canon poético tradicional:

La llegada del poeta-campesino a la ciudad o a las oficinas salitreras implica cambios fundamentales para la poesía de tradición oral que él acostumbraba a cantar en zonas rurales. La poesía oral se expresaba frente a un público conocedor de los grandes temas de la poesía tradicional y que participaba en el arte del poeta; de modo que el poeta guiaba sus improvisaciones de acuerdo a las reacciones del público, haciendo de esta práctica poética un acto dinámico de creación conjunta. La ciudad, en cambio le impone al poeta oral la escritura como la vía de transmisión propia de su quehacer. El paso de la oralidad a la escritura supone un nuevo público: lector, desconocido, que le exige temas nuevos con respecto a los grandes temas tradicionales" (Orellana 102).

5 En el ámbito hispanoamericano, cumplió función semejante, por ejemplo, el corrido mexicano, especialmente, en el período de la Revolución; así también, un amplio repertorio folclórico latinoamericano, como las payas, ritmos andinos, zambas o canciones populares.

6 El conjunto Quilapayún ha recuperado este carácter al musicalizar el poema "Canto de venganza". Recuérdese:

Canto a la pampa la tierra triste

réproba tierra de maldición

que de verdores jamás se viste

ni en lo más bello de la estación. 
En suma, como sostiene Zumthor: "Un poema compuesto por escrito, pero representado oralmente, cambia por este motivo de naturaleza y de función, como inversamente cambia por ese mismo motivo un poema oral recogido por escrito y difundido bajo esa misma forma" $(82)^{7}$. Se trata, en cierta manera, de una verdadera descendencia juglaresca, a la manera del romancero ${ }^{8}$ o trovadoresca que dará origen a toda la poesía popular hispánica y latinoamericana y que animará el quehacer cultural y cotidiano de los pampinos. Es, por ejemplo, el caso de los versos recogidos por Augusto Rojas Núñez en sus Crónicas pampinas, versos que testifican la oralidad popular dominante, según lo declara el propio compilador:

No hemos alcanzado a conocer los cantores de guitarrón. Solo hemos oído relatar interesantes pasajes de los que recorrieron muchos pueblos, alegrando a sus oyentes con sus producciones, con el derrame lírico, si se quiere, de sus cerebros privilegiados, (digamos así) porque en su mayoría estas personas, carecían de educación, pero les acompañaba un don de percepción, de recursos de la rima que les distinguía (48-49).

Luego cita una 'versaina', según dice, que es, en realidad, una estructura compuesta por décimas espinelas ${ }^{9}$, encabezadas por una cuarteta, cuyos versos sirven de glosa a cada una de las estrofas que le siguen, estructura que fue muy popular en el siglo XVII:

No hay pluma con qué escribir

lo que hoy día está pasando, se encuentra el rico robando al pobre para vivir.

Desgraciado el que trabaja

Acá, por las oficinas, de cuyas reglas mezquinas

no saca el pobre ventaja;

el rico no se relaja

en robar, quiero decir

bien puede ver sucumbir

al pobre, en lances estrechos, para narrar estos hechos

no hay pluma con qué escribir (49).

7 Véase, Poesía y Oralidad (2002) de Mauricio Ostria González.

8 Que "no solo es épico-heroico en lo que deriva de las primitivas gestas: él por sí solo contó asuntos nacionales después que la epopeya extensa antigua trató de informar al pueblo de los sucesos que ocurrían y preocupaban a la nación" (Menéndez Pidal 15.)

9 La décima o décima espinela: inventada por Vicente Espinel (s. XVI), está constituida por octosílabos, dos redondillas de rima abrazada con dos versos de enlace (abbaaccddc). 
El contenido de estos versos alude al mismo contexto que enmarcará los sucesos de Santa María. Se emplean, como se ve, formas reconocidamente tradicionales para la expresión de las quejas sociales, compartidas con su auditorio (o lectores), organizadas bajo el motivo, también tradicional, de la superabundancia de lo real, frente a las limitaciones de la palabra (dicha o escrita): "para narrar estos hechos / no hay pluma con qué escribir".

Igual estructura estrófica (décimas compuestas de redondillas, encabezadas por una cuarteta, cuyos versos sirven de glosa), presenta el poema "Sin patria y sin bandera", que ya se refiere al episodio trágico de Santa María, y que expresa la profunda decepción y rechazo por la injusticia institucionalizada:
¡Adiós! Zona salitrera ¡adiós! país desgraciado, de ti me voy expatriado renegando la bandera.
Clamando contra el infierno de la explotación mezquina más salvaje y asesina, el obrero ante el gobierno reclamó contra su ruina, y éste los mató en montón con más saña que una fiera, probándoles que es tontera ampararse en la razón, ¡adiós! Zona salitrera.

El general sanguinario con saña y alevosía, hizo la carnicería entre el pueblo proletario, probándole no existía constitución ni derecho, ante la razón de Estado de proteger al malvado; por lo cual quito mi pecho ¡adiós! país desgraciado. De esta nación sin honor Tendrán todos que emigrar Para poder protestar del gobierno y su rigor en el arte de matar, por lo cual declaro al mundo que ya estoy desengañado y contra la patria airado digo con odio profundo de ti me voy expatriado 


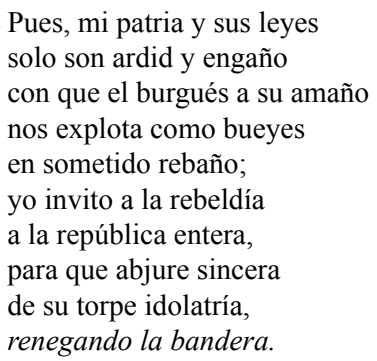

(Cit. en González et al. 414-415)

En "Canto de venganza", en cambio, se utiliza la cuarteta cruzada (ABAB) con versos regulares decasílabos, también de raigambre tradicional:

Benditas víctimas que bajaron desde la pampa llenas de fé a su llegada lo que encontraron la ruin metralla tan solo fue.

(Cit. en González et al. 413)

La poesía popular relacionada con el episodio de Santa María no es fácil de recuperar. Gracias al trabajo investigativo de González Miranda, Illanes y Moulián, de Bravo Elizondo (1997) y de Núñez Pinto (1998), hemos podido acceder a algunos de esos textos, publicados en periódicos de la época, entre 1908 y 1910. Algunos de ellos son: "Sobre la Horrible Matanza de Iquique" e "Indignado el Pueblo Obrero...", de Juan Bautista Peralta; "Canto a los Trabajadores" de Felipe Turati; "Sin Patria y Sin Bandera", de Arturo Segundo Encalada; "Hoja de Laurel" de Luis Olea ${ }^{10}$; "Canto de Venganza" "11 de Francisco Pezoa. Sin duda, la aproximación a la lírica pampina vinculada al episodio de Santa María permite una mirada desde dentro de los protagonistas, sucesos y sentido de la tragedia y, por ende, su confrontación con las versiones oficiales y periodísticas a que dieron lugar aquellos hechos. Los textos destinados a relatar, dramatizar o poetizar la tragedia, enfatizan la relación escritor-lector, intérprete-oyente, poniendo de relieve su carácter apelativo; manifiestan una intencionalidad persuasiva, que se tematiza y concreta en las diferentes instancias textuales. Particularmente, la representación poética de los sucesos de Santa María construye una relación plural (colectiva) entre las voces emisoras y el requerimiento de una recepción masiva. Es, precisamente, esto lo que marca la

10 La versión que recoge Bravo Elizondo y que atribuye a Luis Olea (uno de los dirigentes y sobrevivientes en la matanza de Santa María), difiere en los cuartetos, de la compilada como anónima por González Miranda et al.

11 El texto es también conocido por la versión musicalizada por el grupo Quilapayún y por la recopilación de Bravo Elizondo y Guerrero, con el título de "Canto a la Pampa". 
diferencia entre tales escritos y otras producciones poéticas, en que se busca más bien una relación 'íntima' y 'personal' entre emisor y receptor. Por otra parte, siguiendo también una larguísima tradición de la poesía popular, estos textos construyen un sujeto enunciante que asume tanto el rol de cantor, como el de juglar o pregonero, que puede cantar o contar, como lo hará más tarde el hablante del Canto general nerudiano o las voces que asumen la Cantata Santa María. Se recupera así, como lo recuerda Borges, la doble función del poeta: "antiguamente el poeta era lírico pero también narrador" (61).

La naturaleza luctuosa de los hechos cantados y las tristes circunstancias que condicionan su escritura, constituyen la programación básica de esta poesía, como lo declara el poeta popular Juan Bautista Peralta, en sus versos "Sobre la horrible matanza de Iquique":
Hoy la Lira Popular
sumamente acongojada,
narra la horrible matanza
en Iquique consumada.

(Cit. en Núñez 232-233)

La relevancia histórica y el carácter trágico de los sucesos tematizados en estos textos otorgan primacía a la función referencial, aunque, ciertamente, las funciones apelativa y expresiva no carecen de importancia. En tal sentido, el mundo se representa como un infierno gobernado por relaciones de poder abusivas y destructoras. Así, en "Sin Patria y sin Bandera":

Clamando contra el infierno

de la explotación mezquina

más salvaje y asesina, el obrero ante el gobierno reclamó contra su ruina, y este los mató en montón con más saña que una fiera...

(Cit. en González et al. 414-415)

La horrenda carnicería que en Iquique han consumado, la protesta ha levantado de todo el mundo, a fé mía tan solo la burguesía ha aplaudido al carnicero.

(Cit. en Núñez 233) ${ }^{12}$

12 El texto sin nombre pertenece a Juan Bautista Peralta. 
Asimismo, los textos suelen manifestar un fuerte carácter apelativo, un desesperado llamado, a veces con tono de consigna, que insta a una respuesta solidaria y hasta violenta, ya sea a través de una voz colectiva, en primera persona plural: "Maldigamos..., suprimamos..." (Cit. en González et al. 414); ya de una voz individual, en primera persona: "Pido venganza..." (Cit. en Núñez 234); o de una voz impersonal, en tercera persona: "venga la divina espada..." (Cit. en Núñez 233).

En todos los textos se configura la visión del pampino como héroe-mártir colectivo. Así vemos en "Sobre la horrible matanza de Iquique":

En esa ciudad gloriosa
teatro ayer del heroísmo,
hoy cuna del despotismo
se mata en forma horrorosa.
Se fusila y se destroza,
a la multitud explotada
sin haber obrado nada
que mereciera tal suerte.

(Cit. en Núñez 232)

Se puede observar que el cantor, por un lado, despliega la relación temporal pasadopresente para expresar un proceso de degradación que le permite oponer un momento de gloria épica (la Guerra del Pacífico) a un momento de tragedia vergonzosa (la matanza): el paraíso se ha trocado en infierno ("ciudad gloriosa/ teatro ayer del heroísmo; hoy cuna del despotismo"). Por otro, asume una actitud enjuiciadora y denunciante, remarcada por el uso de formas verbales que denotan agresividad o fragilidad destinados respectivamente a victimarios (sujetos activos): "se fusila y se destroza", y a víctimas (sujetos pasivos): "se mata en forma horrorosa/a la multitud explotada", destacándose su inocencia: "sin haber obrado nada/que mereciera la muerte".

Siguiendo la misma tradición popular, la sintaxis de los versos y estrofas es simple, apoyada en estructuras bimembres que balancean acompasadamente el ritmo, sin encabalgamientos, ni hipérbatos. Todo apropiado a la memorización y al canto. Las figuras retóricas corresponden también a elaboraciones básicas con énfasis en epítetos polares, vinculados a la situación referencial y a la visión dualista de los sujetos. Así, en los ejemplos siguientes:

Suprimamos la frontera

Que a los pueblos hace arteros,

Enemigos y extranjeros

No están fuera; están aquí.

¡Guerra al reino de la guerra!

¡Muerte al reino de la muerte!...

(Cit. en González et al. 414) ${ }^{13}$

13 Fragmento de "Canto a los trabajadores". 
Pido venganza para el valiente que la metralla pulverizó, pido venganza por el doliente, huérfano triste que allí quedó.

(Cit. en González et al. 413) ${ }^{14}$

...En aras del pueblo obrero venga la divina espada y acabe con la poblada militar alma de hiena.

(Cit. en Núñez 233) ${ }^{15}$

\section{LA CANTATA DE SANTA MARÍA}

No hay que ser pobre, amigo, es peligroso. No hay ni que hablar, amigo, es peligroso. (Luis Advis s/p) $)^{16}$

Después de un largo período de latencia y hasta olvido, la Cantata Popular de Santa María de Iquique, de Luis Advis, recupera, definitivamente, con notable éxito y eficacia poética el episodio trágico para el imaginario nacional. Posiblemente, esta obra de doble codificación (literaria y musical) sea una de las más significativas en la historia de la música popular chilena; conjuntamente, constituye un documento histórico, no solo por la historia contada y cantada, sino por el contexto en que se produjo: el advenimiento del gobierno popular de Salvador Allende. La Cantata pertenece a la poesía popular, pero también al neofolclore andino y a la canción 'protesta'; se arraiga en el mundo del salitre, pero se proyecta como épica proletaria en testimonio de las luchas de los trabajadores chilenos. Por este camino, la Cantata parece adentrarse por los senderos de la utopía:

La tierra será de todos también ha de ser el mar Justicia habrá para todos y habrá también libertad. Luchemos por los derechos que todos deben tener.

Luchemos por lo que es nuestro, de nadie más ha de ser.

14 Fragmento de "Canto de venganza".

15 Fragmento de "Sobre la horrible matanza de Iquique".

16 Las citas siguientes a La Cantata..., se ciñen al folleto incluido en las Referencias. 
Al igual que en la producción poética popular pampina, los aspectos semánticos de la Cantata revelan una importante vinculación con el contexto y un fuerte carácter apelativo que sobrepasa las puras dimensiones textuales: "Ustedes que ya escucharon / la historia que se contó / no sigan alli sentados / pensando que ya pasó...”. Pero, claramente, la Cantata, por las calidades de forma y significado, trasciende el ámbito más o menos local de la lira popular, y proyecta su sentido y su vigencia más allá, incluso, de las fronteras nacionales y aun latinoamericanas, para configurar un mensaje de valor universal ${ }^{17}$.

El texto, en verso y partitura, está dividido en nueve partes: dos pregones en voces plurales (inspirados en la música de raíz folclórica) ${ }^{18}$ que abren y clausuran el relato: "Señoras y Señores venimos a contar aquello que la historia no quiere recordar..."; cuatro canciones, cuyos motivos temáticos son la vida del obrero salitrero, la ilusión del viaje a Iquique, el peligro que tras varios días de huelga se hacía sentir en ellos y el lamento emanado de la infausta suerte que los acompañó hasta su final; un interludio cantado ${ }^{19}$ que expresa los encontrados sentimientos de los pampinos a su llegada al puerto, frente a la solidaridad de los pobres y el desdén de los ricos; una canción letanía ${ }^{20}$ que es una súplica cuyo ritmo y tonalidad adquieren la forma de un réquiem en el que se enfatiza el número de víctimas; y una canción final, que se articula como último movimiento e intenta, con un ritmo acelerado, a base de arreglos corales canónicos, llamar la atención de los lamentables acontecimientos en forma de arenga para incitar a la lucha social. La composición incluye, además, cinco relatos en verso (sin música), que resumen los acontecimientos históricos en una breve línea de tiempo, desde el origen del conflicto hasta su desenlace trágico. Asimismo, entre las partes cantadas o recitadas se intercalan cuatro interludios y un preludio, puramente musicales, de estilos y formas diferentes, muy eficaces en la creación de la adecuada atmósfera que colorea los diferentes momentos o episodios.

La denominación de la obra denota dos aspectos aparentemente opuestos: por un lado, el carácter de 'cantata', que liga el arte poético con el arte musical sacro, especialmente coral; por otro, el adjetivo 'popular', que enfatiza, más allá de la complejidad estructural de la composición, la temática de raigambre obrera y su inscripción, a través del conjunto Quilapayún, a quien está dedicada, en el movimiento de "La nueva canción chilena".

17 Sin duda, la oportunidad que el clásico disco de vinilo brindó para que la Cantata trascendiera fronteras y límites puramente textuales se vio, además, beneficiada por la popularidad de los intérpretes, el auge del neofolclore, el reposicionamiento y punto más álgido que alcanzó el discurso de las contradicciones sociales y políticas del Chile de los años setenta, entre otros factores.

18 El 'pregón' es de origen popular y se vincula a los gritos y cantos callejeros con que los vendedores y trabajadores ambulantes pregonaban sus mercancías o servicios.

19 Breve composición -instrumental con o sin canto- que se ejecuta entre dos corales.

20 Serie de alabanzas y súplicas ordenadas, repetidas y concordes entre sí, por las que se ruega a Dios y su madre Santa María. Etimológicamente la palabra letanía proviene del vocablo griego litanueo, que significa súplica o rogativa. 
Ciertamente, el grupo Quilapayún refleja en su trabajo artístico una perfecta simbiosis entre raíces populares y procedimientos doctos, cuestión que comparte absolutamente con la Cantata. Así lo declara, el propio Luis Advis:

Esta obra, dedicada al conjunto Quilapayún, fue escrita siguiendo las líneas generales de una Cantata Clásica. Hay sin embargo, variantes que se refieren a:

Aspectos temático-literarios: el motivo religioso tradicional ha sido reemplazado por otro de orden social y realista.

Aspectos estilístico-musicales: sin dejar de lado la tradición europea, a ella se han amalgamado diversos giros melódicos, modulaciones armónicas y núcleos rítmicos de raíz americana o hispano americana.

Aspectos instrumentales: de la orquesta usual solo se han conservado el bajo (violoncillo y contrabajo) a modo de apoyo, agregándose a él dos guitarras, dos quenas, un charango y un bombo.

Aspectos narrativos: el Recitativo clásico, cantado, se ha sustituido por un Relato hablado que, sin embargo, contiene elementos rítmicos y métricos, con el objeto de no romper el total sonoro (Advis $\mathrm{s} / \mathrm{p}$ ).

La Cantata relata de manera sucinta y en verso, la tragedia de Santa María. Los hechos se disponen a la manera épica, es decir, según una malla axiológica que divide a los actantes en dos bandos que contraponen sus proyectos: las víctimas (obreros pampinos y sus familias) y los victimarios (empresarios salitreros, el poder político y militar), y en donde las voces narrativas y líricas asumen el punto de vista de las víctimas a través de las acciones y atributos que se distribuyen en dualidades antitéticas.

La configuración musical y lírica del texto supone la supresión de una serie de elementos contextuales que pudieran ahondar en detalles descriptivos o explicaciones históricas. La estrategia textual se centra en el desenlace hacia el que se avanza rápidamente a través de fragmentos marcados por la tensión dramática de los breves episodios o escenas.

El "Pregón" introductorio, junto con situar la acción, incluye dos motivos tradicionales de las narraciones históricas: salvar del olvido hechos notables y restituir la verdad sobre esos hechos:

\author{
Señoras y Señores \\ Venimos a contar \\ Aquello que la historia \\ no quiere recordar. \\ Pasó en el Norte Grande, \\ Fue Iquique la ciudad. \\ Mil novecientos siete \\ marcó fatalidad. \\ Allí al pampino pobre \\ mataron por matar. \\ Seremos los hablantes \\ diremos la verdad...
}


La conclusión, en tanto, advierte (proféticamente) sobre peligros futuros:

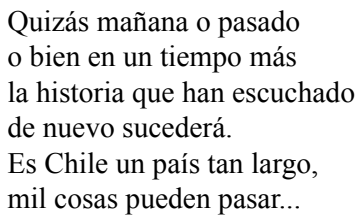

El clima trágico se construye, básicamente, con dos elementos: la adjetivación casi siempre depresiva ('muerte amarga', 'historia de duelo', 'fogón mustio', 'obrero sin cara', 'niño triste', 'choza mortecina', 'castigos humillantes', 'silencios gastados', 'destrozados lamentos', 'casas desposeídas', 'tierra amarga', etc.) y los augurios lamentables: “...Y comienza a cantar mi voz / con temples de algo fatal... / Lo que siento en esta ocasión / lo tendré que comunicar, / algo triste va a suceder, / algo horrible nos pasará...”

El discurso de la Cantata combina elementos poéticos y ficticios con referencias históricas y geográficas. Esta mezcla supone un proceso de mitificación de los sucesos que, desde una perspectiva histórica canónica se pueden leer como distorsiones o inexactitudes (alusiones al número de muertos ${ }^{21}$, discursos públicos de personajes, etc.). Por ejemplo, la pampa se personifica ("El desierto me ha sido infiel, solo tierra cascada y sal...") y asume los rasgos de espacio negativo y ominoso conforme al tono general del relato y a la tradición de crónicas y relaciones ${ }^{22}$ :

El sol en desierto grande

y la sal que nos quemaba

el frío en las soledades.

camanchaca y noche amarga

el hambre de piedra seca

y quejidos que escuchaba

la vida de muerte lenta

y la lágrima soltaba.

La ciudad, por su parte, parece condensar la oposición paraíso-infierno ("Dicen que Iquique es grande/ como un Salar, / que hay muchas casas lindas/ te gustarán", versus "Mientras tanto las casas/ eran cerradas, / miraban solamente/ tras las ventanas. / El Comercio cerró/ también sus puertas, había que cuidarse/ de tanta bestia"). La Escuela Santa María se convierte en el espacio del sacrificio ("La Escuela Santa María/ fue el exterminio/ de vida que se moría, / solo alarido/...”). Finalmente, los pampinos

21 Por ejemplo, hay serias disputas entre historiadores, cronistas y testigos en relación con el número de muertos.

22 Véase, Visión (2004) de Mauricio Ostra. 
funcionan como arquetipos victimizados y las autoridades civiles y militares, como figuras victimizadoras.

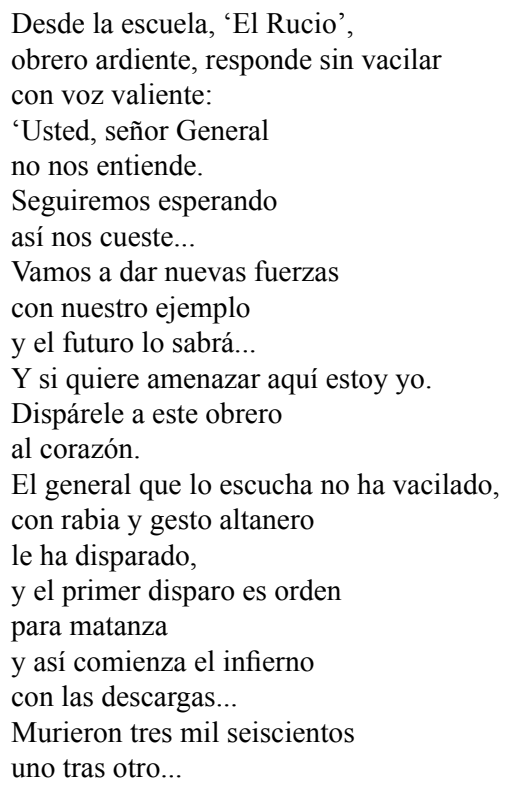

En la construcción de versos y estrofas se emplean, preferentemente formas y combinaciones tradicionales (el romance, la seguidilla, la cuarteta) y también, especialmente en los relatos, los cuartetos endecasílabos. En cuanto a los recursos verbales sonoros, predomina la rima asonante en diversas combinaciones y abundan las reiteraciones de todo tipo (aliteraciones, anáforas, series, gradaciones, estribillos). Ejemplo elocuente son los versos de la Canción letanía, que se construye sobre la base de la repetición del número de muertos (tres mil seiscientos) y de la expresión "uno tras otro", reiteraciones que, apoyadas en las variaciones ('ensordecidos', 'enmudecidos', 'asesinados'), no solo intensifican, y aceleran el ritmo de la secuencia en el momento culminante del relato, sino que parecen multiplicar al infinito el acto sacrificial.

Murieron tres mil seiscientos uno tras otro.

Tres mil seiscientos mataron

Uno tras otro.

Serían tres mil seiscientos ensordecidos.

Y fueron tres mil seiscientos enmudecidos.

Tres mil seiscientas miradas 
que se apagaron.

Tres mil seiscientos obreros

Asesinados.

Por su doble codificación (verbal/musical) que, además, posibilita una fuerte tendencia a la oralización de la escritura y por su naturaleza épico-lírica, la Cantata presenta diferentes voces, algunas propiamente líricas (singulares o plurales) manifestadas principalmente en pregones y canciones (solos y coros), y otras claramente narrativas (relatos recitados o cantados). También están las voces de algunos personajes (el general, el rucio, el pampino viejo que asume el papel de oráculo) y las voces anónimas de los pampinos: singulares ("Vamos mujer, partamos a la ciudad...") o plurales ("Hasta Iquique nos hemos venido / pero Iquique nos ve como extraños").

La narración se inicia con un narrador plural que enfatiza su carácter oral en la apelación al auditorio: "Señoras y Señores / venimos a contar..." El foco del relato varía constantemente desde una perspectiva más abarcadora (semejante a la del narrador tradicional, omnisciente) a una más restringida a la mirada y al saber de los sujetos individuales o colectivos. Esto es lo que permite, en el primer caso (perspectiva del narrador), describir lugares, establecer hechos y fechas, pero, sobre todo, ironizar, por ejemplo, respecto de la dignidad del general, o contraponer en una relación escalofriante el juego inocente de un niño a lo horrendo del posible hallazgo: "Un niño juega en la Escuela / Santa María. / Si juega a buscar tesoros / ¿qué encontraría?”. Y, en el segundo caso (perspectiva de los personajes), someterse al juego de expectativas (esperanza/frustración, deseo/realidad) que impulsa la acción de los huelguistas en su desplazamiento al puerto. En este plano, se da, asimismo, la existencia de monólogos y diálogos en los momentos más intensamente dramáticos o emotivos de la Cantata.

\section{SANTA MARÍA EN LA NOVELA DEL SALITRE ${ }^{23}$}

Silva Renard ordenó el fuego. Las ventanas temblaron. La puerta fue un corazón mordido por el crepúsculo y la muerte (Andrés Sabella 129).

Sin contar esa especie de relato por entregas que constituye la serie de crónicas y noticias a que dio lugar la gran huelga en los periódicos nacionales y locales ${ }^{24}$, ni tampoco los informes y comunicaciones oficiales, ni los testimonios orales y escritos de carácter más

23 Por esta vez, dejamos de lado las producciones dramáticas sobre el tema, que incluye textos como Santa María, de Elizaldo Rojas (1966), Santa María del Salitre, de Sergio Arrau (1989) y una serie de otras propuestas teatrales y musicales.

24 El Pueblo Obrero, El Tarapacá, El Trabajo, El Mercurio, El Nacional, La Patria. 
bien privado, existe un documento fechado el 15 de febrero de 1908, a menos de dos meses de los acontecimientos, cuyo autor firma como Leoncio Marín, que fue publicado presuntamente de manera clandestina (no lleva pie de imprenta) ${ }^{25}$. Se trata del texto 21 de diciembre (Compendio y relación exacta de la huelga de pampinos desde su principio hasta su terminación. Detalles interesantes. Estadística de las víctimas), cuya importancia radica en que es, presumiblemente, la primera narración completa ${ }^{26}$ de los sucesos de Santa María (transcurridos menos de dos meses), contada desde la perspectiva de las víctimas. Esto, a pesar de que el autor declara en el prólogo ("Cuatro letras”) que:

Al emprender esta publicación no nos hemos propuesto escribir la historia de las luctuosas escenas del 21 de Diciembre del año último. [...] Nuestro objeto, por ahora, no es otro que hacer una narración desapasionada y, en lo posible, exacta de lo sucedido, como quien escribe la crónica de un trascendental acontecimiento a fin de que no se extinga la memoria de los sucesos...” (Marín 3).

Efectivamente, muy pronto, el lector percibe que el cronista se identifica con la causa obrera y no pierde oportunidad para establecer el evidente contraste entre la actitud pacífica de los pampinos y la violencia ejercida por los jefes salitreros y sus representantes. El texto, sin embargo, respeta escrupulosamente, el orden cronológico de los acontecimientos y rescata documentación importante para comprender las dimensiones reales del conflicto.

El relato se organiza cronológicamente, desde el sábado 14 hasta el domingo 22 de diciembre ${ }^{27}$. Se alude al origen de la huelga, en la oficina de San Lorenzo, donde tres mil obreros (chilenos, peruanos y bolivianos) deciden marchar a San Antonio y luego a Zapiga

25 Una segunda edición del texto acaba de publicarse, a cargo de Miriam Salinas Pozo, y presentada por Bernardo Guerrero.

26 Concluido este trabajo, Bernardo Guerrero, incansable en su labor de difusión de la cultura nortina, me hace llegar, con su generosidad habitual, la reedición del libro de Vera y Riquelme: Los mártires de Tarapacá. El texto, sin pie de imprenta, como el de Leoncio Marín, fue publicado cumplido un mes exacto de la tragedia, el 21 de enero de $1908 \mathrm{y}$, por lo tanto, se anticiparía por unos días al de Marín.

27 De manera resumida, la secuencia de los hechos narrados por el texto de Marín es la siguiente:

-Viaje a San Antonio y Zapiga (Sábado 14).

- Descripción del pliego de peticiones formuladas en el Hipódromo de Alto del León (cercanías de Iquique), en presencia del Intendente suplente Julio Guzmán García y de los vecinos Santiago Toro Lorca, Antonio Viera Gallo y Agustín Almarza (Domingo 15).

- Propuesta de la Intendencia: tregua de ocho días; los obreros exigen respuesta en 24 horas. Discusión con Viera Gallo.

- Concentración en la escuela Santa María. Nueva formulación del pliego de peticiones y elección del Comité Directivo de la Huelga (Lunes 16). 
para efectuar una asamblea general. Destaca el gran énfasis que Marín pone en los detalles, tales como la hora de los sucesos, los nombres de autoridades y obreros participantes, el pliego de peticiones, y los discursos obreros, todo lo cual confirma el carácter de testigo presencial del autor en la huelga. Así lo ratifica, por lo demás, él mismo: "Haremos un esfuerzo [...] para describir los sucesos con los detalles que pudimos observar y anotar en

- Desembarco en Iquique del crucero Blanco Encalada y llegada de más obreros (Martes 17).

- Desembarco desde el Esmeralda de noventa hombres de marinería y cuarenta hombres de desembarco (Miércoles 18).

- Llegada desde Huara de 2.000 trabajadores más (Jueves 19).

- Llegada del crucero Zenteno con la comisión enviada por el Gobierno (Intendente Eastman, general Silva Renard y coronel Ledesma). Discurso de Eastman.

- Primeras hostilidades en Buenaventura (las tropas hacen fuego sobre mil obreros aprox. que viajaban al puerto, muriendo siete de ellos) (Viernes 20).

- Extensión de decreto de Eastman con prohibiciones diversas a los manifestantes.

- Extensión de carta del Comité Directivo a la Intendencia (sábado 21).

- Orden de traslado de los huelguistas al local del Club de Sport y negativa de los mismos.

Silva Renard alista sus tropas a las 13:00 horas.

- Concentración de los huelguistas en la escuela Santa María y en la Carpa del circo Zobarán levantada en la Plaza Montt.

- Las familias de la gente pudiente se embarca en los buques mercantes.

- Ledesma, Almarza, Wilson, Aguirre y Silva Renard, seguidos por tropas pertenecientes a distintos regimientos parten a la plaza Montt a las 14 horas.

- Descarga de ametralladoras sobre los obreros. Saldo: 300 muertos y 500 heridos, cifras aproximadas.

- Se lleva a los sobrevivientes al Club Sport. En el camino mueren más obreros lanceados.

- Los muertos son sepultados en un zanjón abierto detrás del hospital. Muy pocos son llevados al Cementerio General.

- Prohibición de prensa por parte de Eastman.

- Correspondencia (en detalle) entre Eastman y Silva Renard. Silva Renard argumenta que los obreros estaban armados con armas blancas y que respondieron al primer ataque con tiros de revólver y rifles (Domingo 22).

- Eastman da su versión al ministro del Interior (días posteriores).

Bajo censura, reaparecen todos los diarios locales a excepción de "El Pueblo Obrero" (que fue clausurado), dando versiones contradictorias.

- Detalle de los muertos llevados al Hospital y de los heridos que se recuperan en diversas casas de la ciudad.

- Detalle de correspondencia, fechada antes y después del día 21 de diciembre. 
el mismo sitio de la masacre" (23). El texto es, también, muy interesante desde el punto de vista estilístico, pues revela la raíz popular del discurso e, incluso, un cierto sentido del humor cazurro de los pampinos. He aquí una muestra: "El citado funcionario que se encontraba como tres en un zapato no sabiendo qué hacer contestó como las chiquillas de quince... prometiendo... prometiendo..." (Marín 8); "Tomándole el mal olor a las anteriores proposiciones todos los trabajadores, en coro, respondieron que no aceptaban pidiendo que se les contestara en 24 horas" (9).

Aunque varias novelas inspiradas en temáticas nortinas aluden al episodio de Santa María (Norte Grande (1944), de Andrés Sabella; La luz viene del mar (1951), de Nicomedes Guzmán; Caliche (1954) y Los pampinos (1956), de González Zenteno), es Hijo del salitre (1952), de Volodia Teitelboim, la primera que lo incorpora como elemento fundamental de su estructura novelesca.

Hijo del salitre se construye a la manera de un relato biográfico que recupera, ficcionalizándolas, la niñez, adolescencia y juventud del dirigente social Elías Lafertte, inmerso en la problemática laboral del salitre, a comienzos del siglo XX, y en el contexto de los inicios del movimiento obrero chileno. En este sentido, Hijo del salitre sigue muy de cerca el modelo de la novela de formación. De modo que se asiste a través de su historia (especialmente en la primera parte) a las distintas pruebas que ha tenido que pasar el protagonista en su proceso de hacerse pampino.

La novela está dividida en cuatro partes. La primera y la última narran, respectivamente, la niñez y adolescencia de Elías Lafertte y su consolidación como joven comprometido con la realidad social de los obreros. Los dos capítulos centrales ("Vamos al puerto"28 y "Sábado Negro") son fundamentales en el proceso transformador de su conciencia y corresponden al relato propiamente de la huelga de los pampinos.

Hacerse pampino, en la ficción novelesca, posee un significado trascendente al mero vínculo cordial con el hábitat; alcanza un sentido sacrificial colectivo que termina subsumiendo las historias particulares en la crónica social de un acontecer trágico (Ostria. Hacerse 97-107). En efecto, Hijo del salitre se abre, a partir de la segunda parte, al drama colectivo que culminará con la matanza de Santa María. De protagonista de un relato biográfico, Elías Lafertte se torna en testigo de una tragedia que terminará por moldear definitivamente su perfil humano. "Elías miró... observó... advirtió... se preguntó... oyó..., sintió..." (297-299), vivo en medio de los muertos:

Toda la plaza estaba inundada de sangre y la muerte vivía particularmente en la escuela. Algunos chicuelos, que miraban aferrados al alféizar de la ventana, se precipitaron a tierra. Otros corrían hacia una y otra bocacalle.

El ruido de la muerte completa y de la muerte a medias llenó el espacio. Los muros de la escuela estaban acribillados.

28 Alusión, sin duda, el poema "Canto de venganza", que se inicia, precisamente, con esa incitación. 
... Trató de moverse. Se dio cuenta de que estaba aprisionado por los cuerpos (...) Sintió que la sangre le mojaba las piernas. Al sacar el brazo izquierdo, el vecino cayó sobre su pecho, con los ojos abiertos. Para él había llegado el cese del fuego. Se le caía encima la montaña de la muerte... (299).

\section{SANTA MARÍA DE LAS FLORES NEGRAS}

...los que caímos acribillados aquella tarde sangrienta; los que con el pucho en la boca y la incredulidad pataleando en los ojos tuvimos que morir (...); los que en medio de estertores, expiramos renegando de Dios y de la patria y que, en el fondo de las fosas comunes de ese cementerio en donde fuimos enterrados como perros (...) aún seguimos revolcándonos y despotricando...

(Rivera Santa 236)

El aporte más significativo de Rivera Letelier a la llamada novela del salitre está en la incorporación de una focalización interna a las voces narrativas y de un lenguaje propiamente pampino. El atractivo de sus relatos radica, en buena medida, en la proximidad (cercanía, familiaridad, naturalidad) con que los narradores -a menudo pobladores del lugar-cuentan sus historias: práctica ejercida desde la precariedad del sujeto marginal, desde un habla popular, socarrona; una retórica hiperbólica, barroca y carnavalesca; una visión que, no obstante la condición miserable de la vida narrada, no exenta de violencia, reafirma la dignidad de la condición humana, en su capacidad de resistencia, de ternura, de humanidad.

En efecto, la mirada de Rivera Letelier, corresponde a quien contempla el mundo desde las ruinas de sus pueblos fantasmas, en un porfiado esfuerzo por sobrevivir, como aquellas sociedades y cofradías de antiguos pampinos, que en los puertos aledaños tratan de repetir los ritos de una cultura ya desaparecida. La Reina Isabel cantaba rancheras (1994) es una verdadera elegía a la vida triste y dolorosa, no obstante entrañable, de las oficinas en decadencia; Himno del ángel parado en una pata (1996), la añoranza de la niñez pampina; Fatamorgana de amor con banda de música (1998) recrea nostalgiosamente la vida 'alegre' del único pueblo libre del desierto salitrero: Pampa Unión. Y Los trenes se van al purgatorio (2000) es una impresionante metáfora del retorno imposible, del gran espejismo que oculta la certeza de la muerte inevitable:

... a ambos lados de la línea férrea comienzan a dibujarse los cascotes de algunas oficinas salitreras abandonadas. Junto a sus ruinas, como flotando a la deriva en la reverberación de las arenas candentes, ondulan sus viejos cementerios de tumbas abiertas. (...). Y mientras su corazón en delirio es perforado por el silbato del tren alejándose, prosiguiendo su irreal itinerario por las ciento cuarenta y dos estaciones espectrales, sus ojos dolorosos miran desvanecerse en el aire, en la ardua luz de la pampa, la silueta transparente, ilusoria, melancólica, del último vagón (Rivera, Los trenes 169 y 191). 
En Santa María de las flores negras, centrada en el episodio trágico, desaparece por completo la voz impersonal del narrador-historiador para dar paso a otra, más fresca, popular e íntima. El narrador ha optado por hacerse cargo de aquellas voces silenciadas por la historia oficial, la voz de los protagonistas anónimos, que representaron la temida otredad $^{29}$ social a principios de siglo: la voz del pampino masacrado:

...aunque se eche mano a todo para olvidarnos [...] sabemos que nuestra muerte no será del todo inútil, y que más tarde o más temprano será contada y cantada al mundo entero, y el mundo entero sabrá que esta matanza perpetrada un 21 de diciembre de 1907, en los recintos de la Escuela Santa María de la ciudad de Iquique, fue la más infame atrocidad que recuerde la historia del proletariado universal (Rivera, Santa $237)^{30}$.

Concorde con la estrategia narrativa de contar la historia desde dentro, asumiendo la o las voces de los pampinos, el narrador en Santa María de las flores negras mantiene su anonimato hasta el final de la novela, donde -a la manera del Juan Preciado rulfiano- se nos revela como uno más de los obreros que marcharon a Iquique a exigir sus derechos y que fueron muertos en la masacre. Lo interesante de este narrador es que asume las voces de todos los demás personajes: es, al mismo tiempo, individuo (en tanto que interpreta los sentimientos y pensamientos de cada uno de ellos) y colectividad (en tanto voz de la clase obrera movilizada). Es más, esta voz colectiva involucra a todas aquellas voces que han sido históricamente "otros radicales" para el discurso oficial chileno (peruanos, bolivianos, argentinos) y los integra en una alteridad común: el proletario.

A la salida del campamento se unen a un grupo de huelguistas que marchan portando carteles y haciendo flamear banderas chilenas, peruanas, bolivianas y argentinas (26).

Hombres de distintas razas y nacionalidades, algunos de los cuales no hacía mucho se habían enfrentado en una guerra fratricida, se unían ahora bajo una sola y única bandera: la del proletariado (29).

Nosotros -dicen impetuosos y excitados- hemos acompañado voluntariamente a los hermanos chilenos en esta larga jornada de paz y justicia, y abandonarlos ahora sería una cobardía y una traición sin nombre; una cobardía y una traición que no estamos dispuestos a cometer de ninguna manera, pues hermanitos (203).

Muchos le volvimos a contestar que preferíamos abandonar Chile antes de volver como esclavos a la pampa. Algunos comenzaron a gritar iQue viva la Argentina!

29 "Cualquier alteridad radical es el epicentro de un terror: el que ejerce sobre el mundo normal con su misma existencia y el que este mundo ejerce sobre él, aniquilándolo" (Baudrillard y Guillaume 197).

${ }^{30}$ En adelante, citamos por esta edición. 
¡Que viva el Perú! ¡Que viva Bolivia! Ante tales exclamaciones, el general perdió los estribos y tratándonos de facciosos y antipatriotas, hizo saber que iba a emplear toda la fuerza (204).

Por esto mismo, el autor deviene minoría discriminada y excluida: en su voz hablan el marginal, la mujer, el niño, el obrero pobre e inculto.

...como el señor Intendente no se había dignado a subir al pueblo, la gente de la pampa ya ha decidido marchar a pie hasta Iquique. Que partirán en una gran columna a la hora del amanecer. Esto lo han sabido por la boca del mismito José Brigg, dice orgulloso Juan de Dios [...]. Gregoria Becerra les cuenta entonces a los presentes que su hijo es amigo personal del obrero anarquista... (36-37).

El narrador asume esta condición y la sitúa en el centro. De modo que las voces de los chilenos pertenecientes a otras clases, así como las de los empresarios extranjeros y las autoridades militares y de gobierno son asumidas por un discurso en tercera persona, a veces en estilo indirecto libre, que nunca se confunde con ellas.

Es preciso tener en cuenta, asimismo, que una de las características fundantes de la otredad radical, como la describe el filósofo francés Jean Baudillard, es ser indestructible aun ante la muerte. De aquí que, los relatos amorosos que intercala Rivera Letelier en la novela, no están puestos allí por mero capricho o solo para entretener al lector: funcionan como contrapunto a la narración principal, a la tragedia. Son relatos de génesis, de nuevos comienzos. Por un lado, la historia fallida de amor entre Olegario Santana y Gregoria Becerra es figura de la historia de toda la masa obrera: se trata de un amor adulto, silencioso, infructuoso, que acaba con la muerte de la mujer y con el regreso de Olegario a su soledad, pero con la verdad que el recuerdo de una mujer real puede imponer al ideal femenino metido en una cajetilla de cigarros... Su fracaso es también el fracaso de todos los trabajadores que han de volver a laborar en las oficinas salitreras sin haber conseguido lo que buscaban, diezmados por la masacre, pero con un nuevo compromiso hacia la verdad, que ha de ser "cantada y contada al mundo entero" (237). Por otra parte, la historia de amor entre Idilio Montaño y Liria María avanza, en cambio, en un sentido completamente contrario al de la secuencia principal. Son jóvenes, apenas sí están involucrados por lazos de parentesco con los reales protagonistas del conflicto obrero, y mientras todos luchan por sobrevivir la travesía a través de la pampa, ellos elevan volantines, juegan y se enamoran. De Idilio nos dice el narrador:

De modo que su reciente amor por Liria María, nacido de manera tan fulminante, lo anda trayendo en tal estado de gracia, que la marcha bien puede darle tres veces la vuelta al mundo que él la hará sin agobios y sin beber una sola gota de agua. Solo le basta la sonrisa lacónica de Liria María para sobrevivir a todo percance, natural, humano o divino (49).

El triunfo sobre la muerte, personificado en los jóvenes, se reconoce especialmente en tres momentos de la narración: 1. El alumbramiento que asisten Liria María e Idilio 
Montaño durante la travesía por el desierto ${ }^{31} ; 2$. El coito de ambos personajes en el mismo momento en que se desatan las descargas de las ametralladoras en la escuela Santa María (213-214); 3. El anuncio del próximo matrimonio de los jóvenes y el apoyo monetario que les da Olegario para que inicien una nueva vida. Idilio Montaño tendrá todo aquello que Olegario siempre quiso: una mujer que "es igualita a la de los cigarros Yolanda" (235) y los ahorros de toda su vida.

El juego que hace Rivera Letelier con el nombre de "María" tampoco es casual. Mientras en la escuela que vio morir a una multitud de obreros, y en la niña muerta, a la que visten como la Virgen, el nombre María encarna el fracaso y la extinción, en Liria María simboliza la persistencia de vida y los ideales más allá de la muerte. Lo dice doña Gregoria: "Se podrá matar al soñador, pero no al sueño" (146).

Hay en este contrapunto del discurso (lo grave y lo alegre; lo trágico y lo romántico) una relación con el carnaval, en tanto éste representa también en sus rupturas y contradicciones, una fuerza renovadora. Precisamente, junto con constituirse como alteridad radical, en relación con los cánones de la sociedad y la cultura oficiales, el pueblo obrero deviene alteridad explosiva y, en esa condición, irrumpe en la geografía y en la historia de manera fulminante en pos de aperturas hacia un nuevo orden (literal y simbólicamente).

Por último, este otro indestructible que es el pueblo se encarna también en el narrador, especie de fantasma obrero que recorre su historia colectiva para revivirla, para recrearla, para hacerla eternamente presente como testimonio concreto de que el sacrificio de los pampinos en Santa María no ha sido en vano.

\section{BIBLIOGRAFÍA}

Advis, Luis. 'Nota' al folleto adjunto a la emisión discográfica de Quilapayún: "Santa María de Iquique". Cantata Popular. Texto y música: Luis Advis/Relator: Héctor Douvauchelle. Santiago de Chile: Warner Music, 1998.

Bahamonde, Mario. Pampinos y salitreros. Santiago: Quimantú, 1973.

Baudrillard, Jean y Marc Guillaume. Figuras de la Alteridad. México, D.F.: Taurus, 2000. Borges, Jorge Luis. Arte Poética. Barcelona: Crítica, 2001.

31 "Cuando un instante después el berrear de la criatura resuena rotundo en el eco de la pampa [...] , al tomar y alzar al recién nacido entre sus manos ensangrentadas, el joven herramentero siente de golpe, con los ojos arrasados en lágrimas, que aunque la marcha se tronche y el movimiento no tenga el éxito esperado, que aunque los gringos pulmoneros del carajo se rían de ellos nuevamente y ganen otra vez como siempre ganaban, él, personalmente, ha logrado algo grandioso: se ha hecho hombre. En estos tres días de huelga ha conocido la férrea solidaridad de los oprimidos, ha encontrado el amor en los ojos de Liria María, y ahora mismo acaba de sentir la indecible sensación de vida palpitando nueva entre sus manos." (54). 
Bravo Elizondo, Pedro. "Santa María de Iquique en relaciones literarias". Revista de Ciencias Sociales (UAP) 7 (1997): 16-23.

Bravo Elizondo, Pedro, et al. Historia y Ficción Literaria Sobre el Ciclo del Salitre. Iquique: Ediciones Campus Universidad Arturo Prat, 2000.

González Miranda, Sergio. Hombres y Mujeres de la Pampa. Santiago: LOM, 2002.

González Miranda, Sergio, et al. Poemario Popular de Tarapacá. Santiago: LOM, 1998.

Marín, Leoncio. 21 de diciembre. Compendio y relación exacta de la huelga de pampinos desde su principio hasta su terminación. Detalles interesantes. Estadísticas de las víctimas. Iquique, s.p.i., 1908; 2a . ed., Iquique, Ediciones Campus de la U. A. Prat-Ediciones El Jote Errante, Gobierno de Chile, C.R. de la Cultura y las Artes.

Menéndez Pidal, Ramón. Flor Nueva de Romances Viejos. Madrid: Espasa Calpe, 1979.

Núñez Pinto, Jorge. "Los Sucesos de Santa María en la Poesía Popular". A Noventa Años de los Sucesos de la Escuela Santa María de Iquique. Santiago: DIVAN/LOM/UAP, 1998. 225-235.

Orellana, Marcela. "Lira Popular: Un Discurso Entre la Oralidad y la Escritura". Revista Chilena de Literatura 50 (1996): 101-112.

Ostria González, Mauricio. "Poesía y Oralidad”. Acta Literaria 27 (2002): 67-75. 111-121.

"Visión nerudiana del desierto nortino". Revista Chilena de Literatura 65 (2004):

"Hacerse pampinos". Anales de Literatura Chilena 6 (2005): 97-107.

Rivera Letelier, Hernán. Los trenes se van al purgatorio. Santiago: Planeta, 2000.

Santa María de las flores negras. Buenos Aires: Seix Barral, 2002.

Rojas Núñez, Augusto. Crónicas Pampinas. Iquique: Edit. El Cóndor, 1936.

Sabella, Andrés. Norte grande.1944. Santiago: Orbe, 1966.

Sánchez Fuentes, Rodrigo. "Iquique: Ciudad, Red y Castigo”. A Noventa Años de los Sucesos de la Escuela Santa María de Iquique. Santiago: DIVAN/LOM/UAP, 1998. 303-313.

Teitelboim, Volodia. Hijo del salitre. Santiago: LOM Ediciones, 2002.

Vera Y Riquelme. Los mártires de Tarapacá. 21 de diciembre de 1907. Iquique: Gobierno de Chile (C. R. de Cultura), U. A. Prat, Ediciones El Jote Errante, 2008.

Zumthor, Paul. Introducción a la Poesía Oral. Buenos Aires: Altea/Taurus/ Alfaguara, 1991.

Palabras clave: Santa María de Iquique, oralidad y escritura, versos populares, Cantata Santa María, novela del salitre.

KEY WORDS: Santa María de Iquique, Orality and literacy, popular poems, Cantata Santa María, Nitrate's novel. 